Artigo / Article

\title{
Hematogônias: Distinção com blastos da leucemia linfóide aguda de células B por citometria de fluxo
}

\author{
Hematogones: Differentiation from B-lineage acute lymphoblastic leukemia by flow cytometry
}

Fátima M. G. Jorge ${ }^{1}$

Jesamar C. Matos ${ }^{1}$

Maria Helena Pitombeira ${ }^{2}$

Francisco D. Rocha Filho ${ }^{3}$

\begin{abstract}
Hematogônias são precursores normais de linhagem B que apresentam características morfológicas e, algumas vezes, imunológicas similares aos linfoblastos das leucemias linfóides agudas (LLA). O objetivo desse trabalho é realizar análise comparativa por citometria de fluxo, utilizando três cores, entre sub-populações de hematogônias e blastos da LLA-B, em crianças. O Grupo 1 constou de amostras de medulas ósseas, não neoplásicas, que apresentaram hematogônias identificadas pela microscopia óptica e o Grupo 2 de casos novos de LLA-B. O painel de anticorpos monoclonais utilizado era direcionado para: CD19, CD10, CD45, CD34, IgM, TdT e CD22. A análise das hematogônias, utilizando como parâmetro a intensidade de fluorescência de CD10 X CD45, mostrou três sub-populações representando células imaturas, intermediárias e maduras. A expressão dos marcadores CD34, IgM, TdT e CD22 reforçou esses achados. Os blastos leucêmicos se apresentaram formando uma única população, com expressão de positividade apenas para antígenos de imaturidade. Considerando não só a presença ou ausência de um determinado antígeno, mas sim a sua intensidade de expressão, verificamos que hematogônias e blastos apresentam perfis imunofenotípicos diferentes. Rev. bras. hematol. hemoter. 2006;28(4): 258-263.
\end{abstract}

Palavras chaves: Hematogônia; citometria de fluxo; leucemia linfóide aguda.

\section{Introdução}

Hematogônias são células precursoras de linhagem B, encontradas na medula óssea, sendo, portanto um constituinte normal na hematopoese., ${ }^{4,9} \mathrm{Em}$ indivíduos saudáveis podem ser detectadas morfologicamente, em número reduzido, em qualquer faixa etária. É mais comum em crianças e vai diminuindo com a idade. Aumentos consideráveis têm sido descritos em casos de púrpura, neuroblastoma e principalmente em crianças portadoras de leucemia, após o uso de quimioterápico ou pós-transplante de medula óssea. ${ }^{6}$ Em doenças tropicais como no calazar é possível encontrar aumento destas células na medula óssea (observação pessoal, 2005). Apesar do seu caráter benigno, as hematogônias apresentam características morfológicas similares às dos blastos da LLA-L1, e a distinção entre essas duas populações celu- lares é geralmente difícil, principalmente quando analisamos amostras de medula óssea de crianças em uso de quimioterápicos. ${ }^{3,9}$

Embora blastos e hematogônias apresentem algumas semelhanças imunológicas, podendo vir a exibir os mesmos marcadores, a imunofenotipagem por citometria de fluxo, utilizando três ou quatro cores, é uma ferramenta elucidativa na distinção entre essas duas populações celulares. ${ }^{12}$

Utilizando esta metodologia estudamos estas duas populações objetivando uma definição mais criteriosa e uma conduta clínica mais adequada, evitando a administração desnecessária de quimioterápicos.

\section{Casuística e Métodos}

O estudo foi realizado no Serviço de Oncohematologia

\footnotetext{
${ }^{1}$ Centro de Referência do Diagnóstico do Câncer da Criança e do Adolescente Dr. Murilo Martins - Hospital Infantil Albert Sabin.

${ }^{2}$ Departamento de Medicina Clínica - Faculdade de Medicina da Universidade Federal do Ceará.

${ }^{3}$ Departamento de Patologia e Medicina Legal - Faculdade de Medicina da Universidade Federal do Ceará.
} 
do Hospital Albert Sabin (Fortaleza-Ce) em amostras de medulas ósseas de crianças (idade variando de 24 dias a 08 anos), divididas em dois grupos: Grupo $1-20$ amostras de medulas ósseas livres de doença neoplásica e que exibiam hematogônias, detectadas pela análise morfológica; Grupo 2 - 10 amostras de medulas ósseas de pacientes com diagnóstico morfológico e imunológico de LLA tipo B, virgem de tratamento quimioterápico. Os esfregaços medulares foram corados pelo Leishmann e analisados por dois citologistas.

A condição de inclusão no Grupo 2 era que, utilizando critérios morfológicos e citoquímicos, essas medulas se enquadrassem na classificação FAB como LLA-L1 ou LLA-L2 e que, levando em conta características imunológicas, fossem identificadas como de linhagem B, de acordo com a classificação EGIL. ${ }^{2}$

Na imunofenotipagem por citometria de fluxo, os dois grupos foram submetidos aos mesmos procedimentos técnicos e foi utilizado um painel com a seguinte distribuição de anticorpos monoclonais: CD45FITC (IQP)/ CD10PE (Coulter) /CD19Cy5PE (Pharmacia); mIgMFITC (DAKO)/ CD34PE (Coulter)/CD19 Cy5PE e cyTdTFITC (Cytognos)/mCD22PE (Coulter) / CD19Cy5PE. A presença do anticorpo monoclonal CD19 em todos os tubos tinha como objetivo a separação da população de células B. O material foi processado utilizandose lise dos eritrócitos para marcação de membrana. No tubo que continha TdT, após a marcação de membrana para CD22 e CD19, foi dada continuidade com a técnica de marcação citoplasmática.

A análise imunofenotípica foi realizada por citometria de fluxo de três cores com contagem de 10.000 eventos na subpopulação com expressão de CD19. A aquisição foi realizada no citômetro FACSCalibur e software CellQuest da Becton Dickinson ${ }^{\circledR}$. Foi realizada optimização com a própria amostra, utilizando CD45 marcado com as três cores (FITC, PE e Cy5PE).

\section{Resultados}

No Grupo 1, as células categorizadas como hematogônias apresentavam-se formando uma população celular com grande heterogeneidade de tamanho. Na maioria das vezes, a faixa citoplasmática era escassa e, quando presente, apresentava-se com basofilia moderada ou fraca e desprovida de inclusões, grânulos ou vacúolos. A cromatina nuclear era densa e homogênea com nucléolos ausentes ou pequenos e indistintos (Figura 1).

Diante da associação de CD45/CD10/CD19 nas medulas ricas em hematogônias, todas as hematogônias amostras avaliadas (100\%) apresentavam uma subpopulação de células expressando CD10(+) de alta intensidade com CD45(+) de baixa intensidade; seguido por outra fração representada por CD10 e CD45 com positividade intermediária e finalmente uma porcentagem de células representada pela expressão negativa e/ou positiva de baixa intensidade de CD10 com expressão positiva de alta intensidade de CD45 (Figura 2). Em nenhum caso foi observada subpopulação que expressasse CD10(+) de alta intensidade com CD45(-). Analisando a mesma associação de anticorpos monoclonais no Grupo 2 verificou-se que a expressão dos blastos leucêmicos se manifestou de uma forma constante. Em todos os casos uma quase totalidade das células (acima de 90\%) formavam regiões ou CD10(+) de alta intensidade com CD45(-) ou CD10(+) de alta intensidade com CD45(+) de baixa intensidade. Em 70\% dos casos foi identificada, além de uma das populações de células acima citada, uma outra representada por pequena percentagem de células expressando CD10(-) com CD45(+) de alta intensidade (Figura 3).

Fazendo uso dos mesmos anticorpos monoclonais, utilizando como parâmetro de análise CD45 X complexidade (SSC), as hematogônias se apresentaram como células de baixa complexidade traduzida pela baixa expressão de SSC.

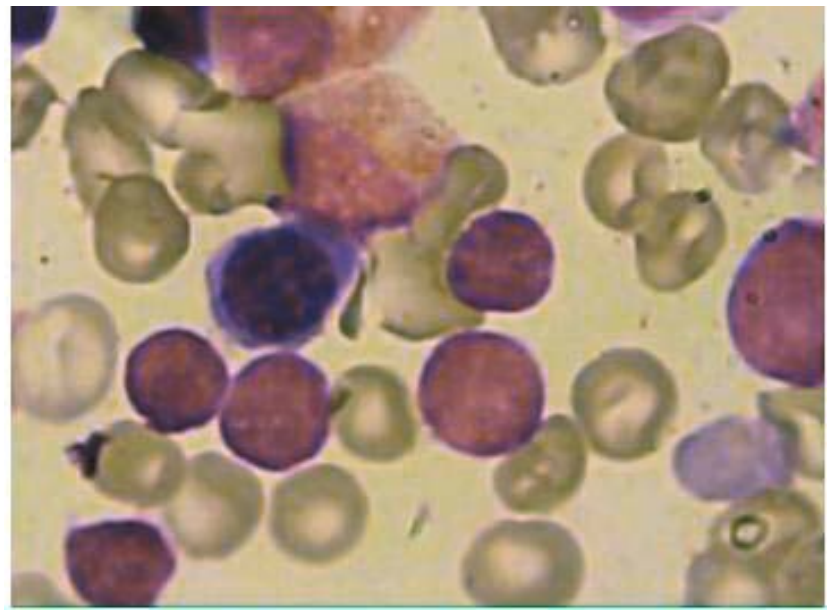

Figura 1 - Hematogônias em medula óssea
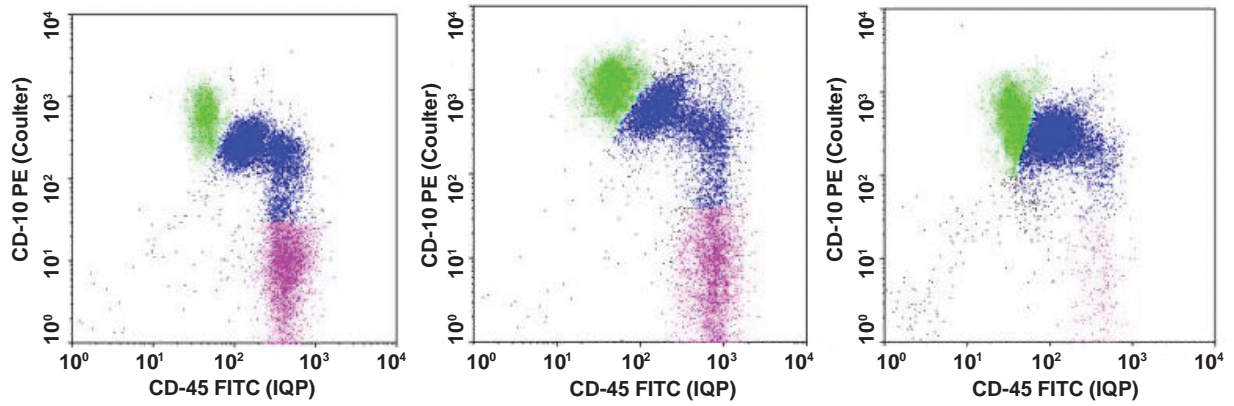

Figura 2 - Expressão e intensidade de fluorescência de CD10 x CD45 em medulas ricas em 

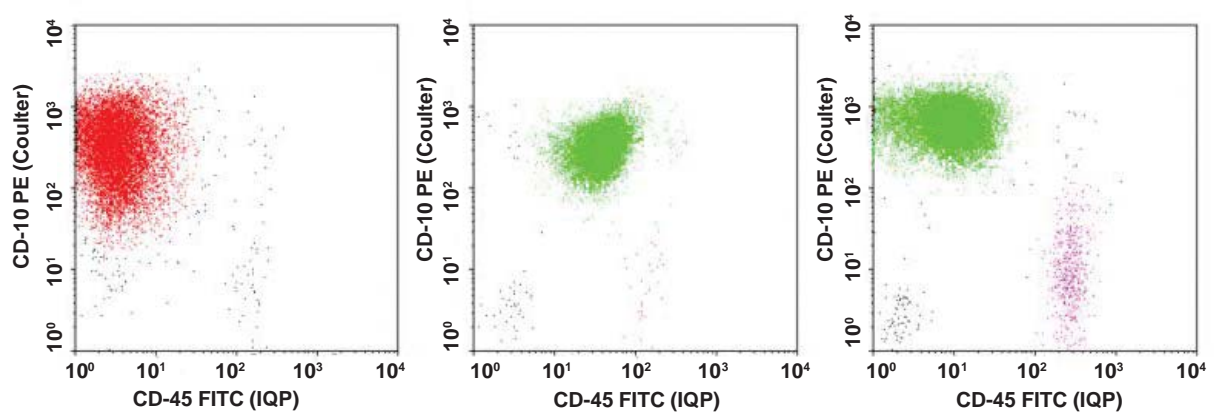

Figura 3. Expressão e intensidade de fluorescência de CD10 x CD45 em medulas de LLAs-B
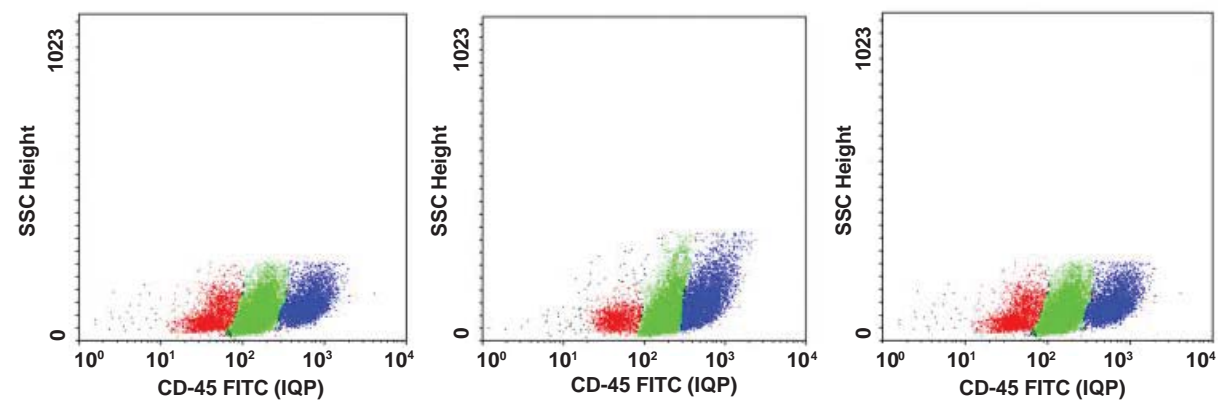

** Células mais imaturas

** Células intermediárias

** Células mais maduras

Figura 4. Análise de medulas ricas em hematogônias utilizando-se como parâmetro SSC x CD45
Essa análise mostrou os três estádios maturativos caracterizados respectivamente pela baixa, intermediária e alta intensidade de expressão de CD45 (Figura 4). Os blastos se comportaram como uma única população de baixa complexidade (SSC) com CD 45(-) ou (+) de baixa intensidade (Figura 5).

A associação de CD34 com IgM demonstrou três populações distintas, em todas as amostras medulares ricas em hematogônias, expressas imunologicamente por CD34(+) com IgM(-); CD34(-) com IgM(-) e CD34(-) com $\operatorname{IgM}(+)$ (Figura 6). Nos blastos, a forte expressão de CD34 se deu em $80 \%$ dos casos; $20 \%$ das amostras se mostraram negativas ou com fraca expressão para esse antígeno. IgM era negativo em $90 \%$ das medulas e um caso isolado apresentou positividade em um pequeno número de células (Figura 7).
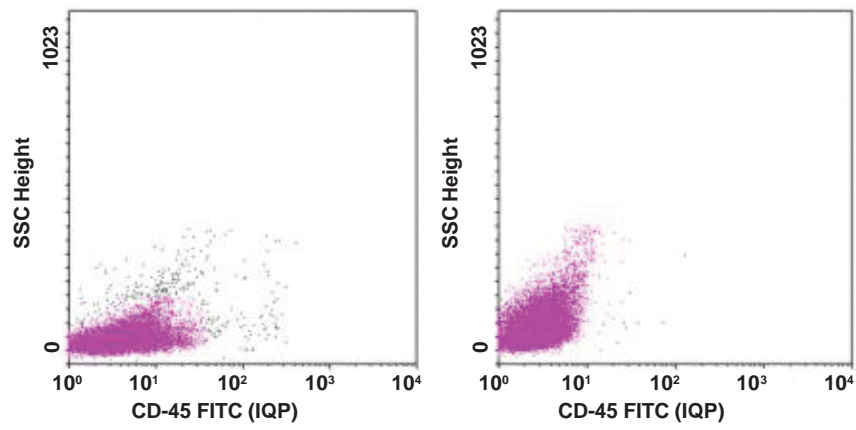

Figura 5. Análise dos blastos de LLA-B utilizando-se como parâmetro SSC $\times$ CD45
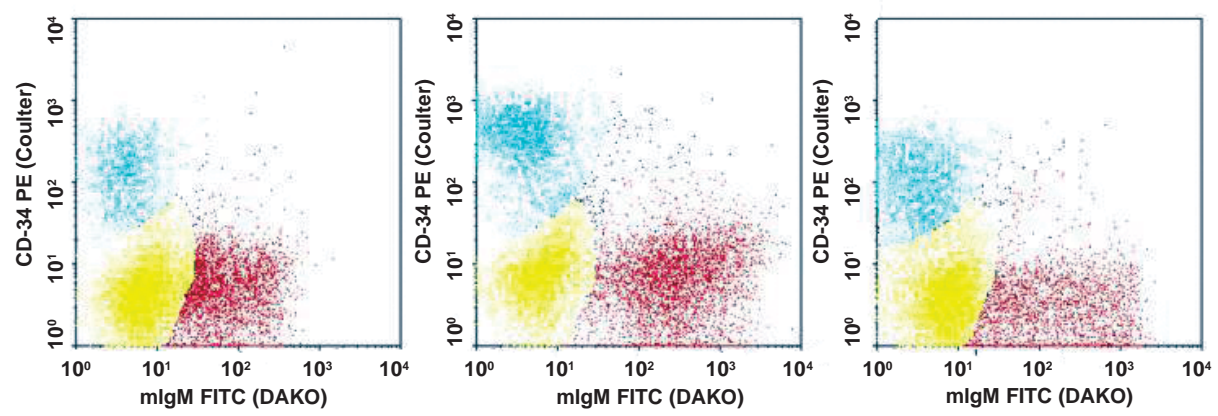

Figura 6. Histograma representando a expressão de CD34 x IgM em medulas ricas em hematogônias
Várias formas de expressão foram observadas diante da combinação de TdT com CD22, no grupo constituído por hematogônias, estratificando as populações em: $\operatorname{TdT}(+)$ com CD22(+) de baixa intensidade; TdT(+) com CD22 (-); TdT(-) com CD22(+) de baixa intensidade; TdT(-) com CD22(+) de alta intensidade e TdT(-) com CD22(-). Verificou-se a expressão de TdT, associado ou não com CD22, em $80 \%$ das aquisições. A expressão de CD22, de alta e/ou baixa intensidade de fluorescência, estava presente em todas as amostras (Figura 8). Na população constituída por blastos, a expressão de CD22 estava presente em todos os casos, formando um único cluster. TdT era positivo em 90\% das amostras (Figura 9).

\section{Discussão}

Hematogônias são células precursoras B, portanto um componente normal da medula óssea. São encontradas em número aumentado especialmente em recuperação de tratamento quimioterápico ou após transplante de medula óssea podendo vir a constituir até mais de $50 \%$ das células medulares. ${ }^{7}$ Esse fato pode criar dificuldades diag- 

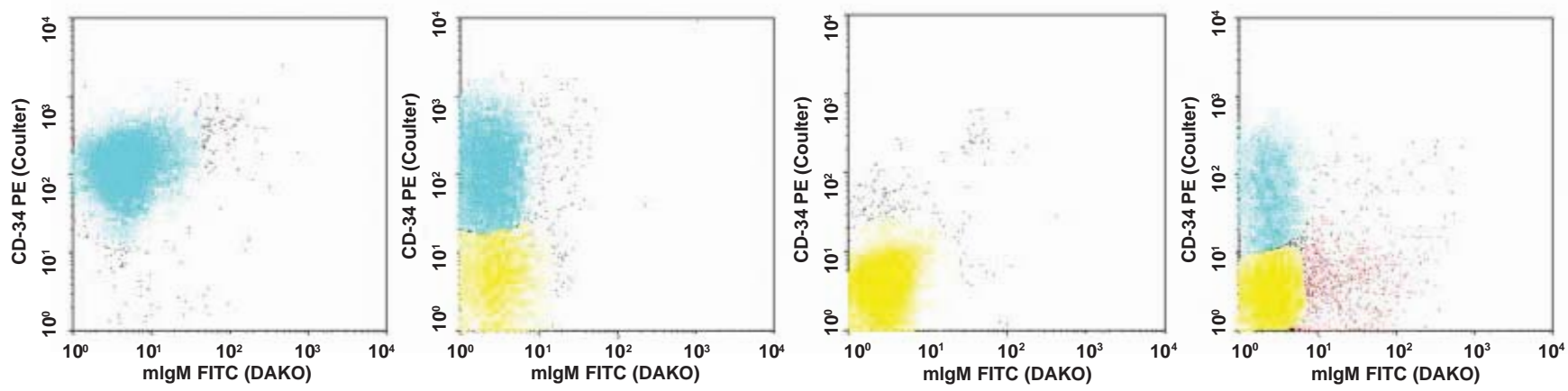

Figura 7. Histograma representando a expressão de CD34 x IgM nos blastos da LLA-B.
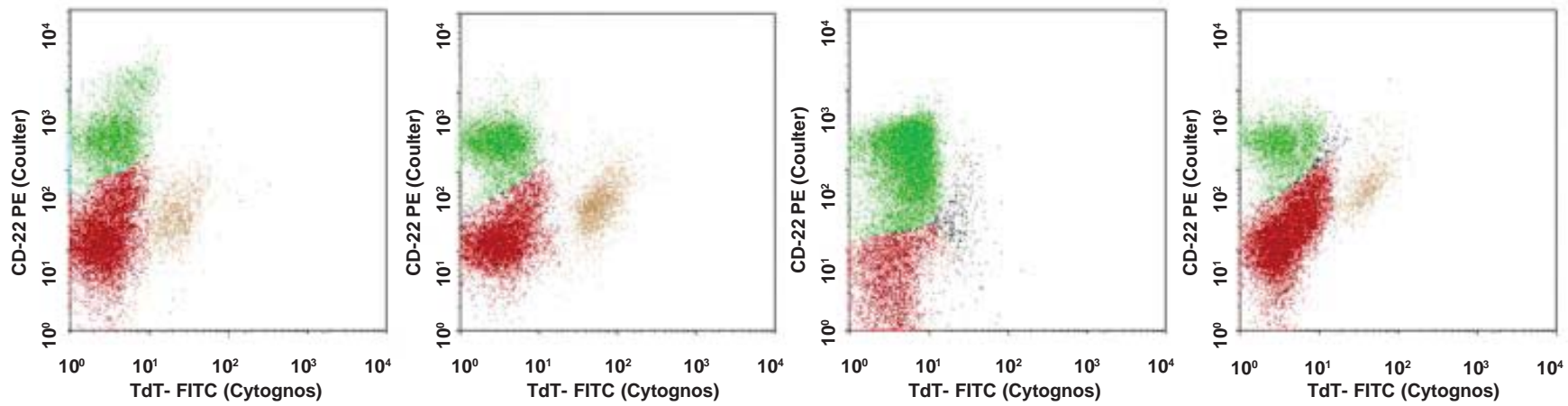

Figura 8. Histograma representando a expressão de TdT x CD22 em medulas ricas em hematogônias
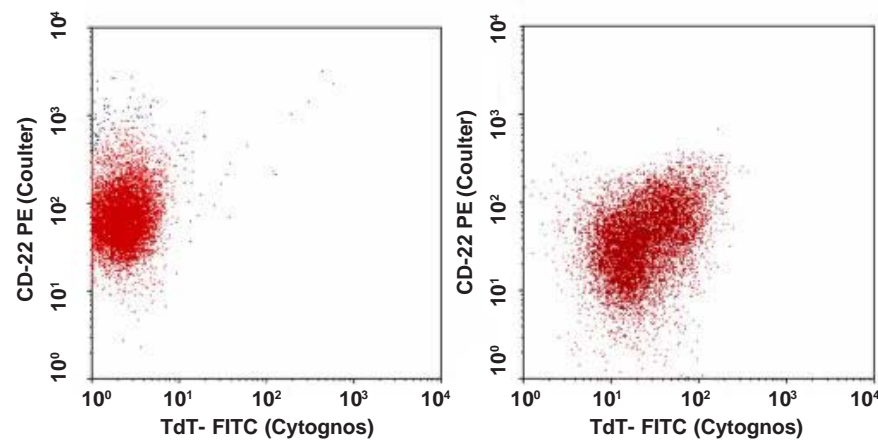

Figura 9. Histograma representando a expressão de TdT x CD22 enos blastos de LLA-B, em pacientes virgens de tratamento

nósticas, já que tanto a morfologia como a imunofenotipagem apresentam características comuns com linfoblastos malignos. ${ }^{5,9}$

Devido às similaridades imunológicas entre hematogônias e linfoblastos, o uso da citometria de fluxo, com uma ou duas cores, não tem se mostrado confiável para distinção entre essas duas entidades celulares. ${ }^{3}$ Critérios morfológicos são sutis e subjetivos. Nosso estudo utilizou imunofenotipagem por citometria de fluxo com três cores, baseado em conhecimentos de que essa técnica tem se mostrado uma ferramenta elucidativa para essa diferenciação, levando em conta não só a presença ou ausência de um determinado antígeno, mas sim a sua intensidade de expressão. ${ }^{7}$

No presente estudo, o uso de CD19 em todos os tubos permitiu realizar análise exclusivamente das células de linha- gem B. A combinação de CD10 com CD45 mostrou que as amostras medulares ricas em hematogônias exibiam um típico espectro de antígenos que definem a evolução normal dos precursores de células B. Essas etapas eram representadas por três regiões: $\mathrm{CD} 10(+)$ de alta intensidade com CD45(+) de baixa intensidade; $\mathrm{CD} 10(+)$ de intensidade intermediária com CD45(+) com intensidade intermediária e CD10(+) de baixa intensidade e/ou (-) com CD45+ de alta intensidade. As três regiões correspondiam a células imaturas, células com maturação intermediária e células maduras, respectivamente. Na maioria dos casos (95\%) predominou a população de células intermediárias seguida por células maduras e finalmente células imaturas.

A combinação desses dois anticorpos monoclonais (CD10 com CD45) permitiu, ainda, fazer outra análise relacionando CD45 com SSC. Os resultados obtidos mostraram três regiões distintas de maturação (imaturas, intermediárias e maduras) traduzidas pela alta, média e intensa expressão de CD45 associado com SSC de baixa complexidade (Figura 4). Esse tipo de expressão reforça os nossos resultados, previamente obtidos, quando analisamos CD10XCD45 e com a descrição feita por Vidriales et $a l^{11}$ referente aos vários estágios do processo maturacional das células B.

A associação de anticorpos direcionados para CD34, antígeno de imaturidade, com anticorpos direcionados para IgM, antígeno de células B maduras, exibiu três regiões correspondendo a células imaturas, intermediárias e maduras representadas pela expressão de CD34(+) com IgM(-); CD34(-) com IgM(-) e CD34(-) com IgM(+), respectivamente. 
A análise realizada usando a combinação de CD22 com TdT mostrou que a expressão de TDT estava presente em 16 das 20 amostras (80\%). A negatividade de TdT em $20 \%$ dos casos reforçam conhecimentos de que apesar desse antígeno ser considerado de imaturidade das células linfóides B e T, sua presença não se faz obrigatória. ${ }^{2}$ A expressão de CD22 se deu em todos os casos confirmando o seu caráter de antígeno de células B. ${ }^{9}$ Muitas vezes foi observada uma dupla intensidade de expressão, fraca e forte, demonstrando que numa população celular constituída por hematogônias existem células menos e mais maduras.

Diante das diversas combinações de anticorpos monoclonais, nosso estudo evidenciou que as hematogônias apresentam um padrão de maturação progressivo onde são observadas células com características de imaturidade juntamente com outras intermediarias e ainda células maduras.

Pesquisa realizada por Longacre et al., ${ }^{6}$ por citometria de fluxo com duas cores, em medulas de pacientes pediátricos ricas em hematogônias, revelou que essas células freqüentemente apresentavam expressão aumentada de CD19, CD10, TdT, HLA-DR e IgM citoplasmática, assim como a Leucemia Linfóide Aguda de células B; entretanto, o padrão de fluorescência para esses antígenos sugeria um espectro de estágios de maturação.

Rimsza et al, ${ }^{9}$ realizando estudo, por citometria de fluxo, em amostras de medula óssea de crianças, ricas em hematogônias, encontraram um espectro de maturação de células B. Em cada caso existia uma proporção relativamente pequena de células muito imaturas TdT(+) e CD34(+); uma fração predominante apresentando CD10(+), TdT(-) e $\operatorname{IgM}(-)$ e uma outra composta por células B maduras $\operatorname{IgM}(+)$. No presente estudo, embora usando uma outra associação de anticorpos, foram obtidos resultados semelhantes aos de Rimsza et al., ou seja: uma população rica em hematogônias é composta predominantemente por células intermediárias, seguida por células maduras e finalmente células imaturas. ${ }^{8}$

McKenna et al., ${ }^{7}$ também fazendo uso de citometria de fluxo, estudaram uma população constituída por crianças e adultos e constataram que, em todos os casos analisados, a população de hematogônias exibia um complexo espectro de antígenos que definiam a evolução normal dos precursores de linhagem $B$.

Na LLA-B, o fenótipo corresponde aos estágios precoces de maturação da célula B. ${ }^{10}$

Apesar de hematogônias e blastos da LLA-B apresentarem antígenos em comum, a distribuição e a intensidade de expressão observadas em histogramas se manifestam de formas distintas.

Nesse estudo, em todos os pacientes portadores de LLA-B os linfoblastos exibiram um amplo espectro maturacional incompleto, divergente do padrão de maturação progressivo observado nas hematogônias.
Diante da combinação de marcadores direcionados para CD10 e CD45, nos dez casos estudados verificou-se uma quase totalidade de células B (acima de $90 \%$ ) formando regiões CD10(+) de alta intensidade com CD45(-) (expressão exclusiva de células neoplásicas) ou CD10(+) de alta intensidade com CD45(+) de baixa intensidade (expressão comum em células neoplásicas, porém não exclusiva), ambas, portanto traduzindo comportamento de células imaturas. Em sete dos dez casos, além de uma das regiões acima descritas, existia uma outra constituída por um número reduzido de eventos com comportamento de células maduras CD10(-) com CD45(+) (de alta intensidade). Na nossa interpretação, essa expressão corresponde a uma pequena população de linfócitos B maduros presentes em medulas de portadores de leucemia, já que na maioria dos casos dessa patologia, a população de células neoplásicas não corresponde à totalidade das células medulares.

A associação de CD34 com IgM reforçou o comportamento de imaturidade característico dos blastos, demonstrado pela região CD34(+) com IgM-. Apesar de CD34 ser um antígeno de imaturidade e freqüente nas leucemias agudas, estudos têm demonstrado a existência de casos de LLA com CD34(-). ${ }^{1,11}$ No nosso estudo identificamos um caso CD34 () e um outro CD34(+) em somente 3,83\% das células.

CD22 estava presente em todas nossas as amostras de LLA-B. Não foi observada em nenhuma amostra dupla intensidade de expressão, como encontrado nas hematogônias, refletindo a parada de maturação em um determinado estágio das células leucêmicas. A expressão de TdT não forneceu recursos que favorecesse a distinção entre blastos e hematogônias, uma vez que estava presente na maioria dos casos nos dois grupos e variando a intensidade de expressão nas duas situações.

\section{Conclusão}

Hematogônias e LLA-B, apesar de expressarem os mesmos antígenos, possuem perfis imunológicos diferentes, baseado na distribuição e intensidade de expressão desses antígenos. Hematogônias apresentam, dentro de uma mesma população celular, um amplo espectro maturacional composto por células imaturas, intermediárias e maduras. O estágio intermediário aparece em maior proporção, seguido por células maduras e poucas células imaturas. Essa estratificação é reproduzida com fidelidade diante da associação de CD45 com CD10. Linfoblastos exibem um espectro maturacional incompleto, representado por células formando uma única população, com características de imaturidade. Citometria de fluxo com três cores, utilizando um painel com poucos anticorpos, nos permite distinguir hematogônias de linfoblastos.

A análise imunológica, associada com a morfológica, proporciona a distinção entre hematogônias e linfoblastos, permitindo não só uma melhor definição diagnóstica, como 
orientando a submissão ou não do paciente ao adequado tratamento quimioterápico.

\begin{abstract}
Hematogones are normal B-lineage cell precursors with morphologic and sometimes immunophenotypic, similarities to neoplastic lymphoblasts. The aim of this work is to compare using flow cytometry sub-populations of B-lineage cells: normal bone marrow precursors (hematogones) and lymphoblasts. Normal bone marrow from patients with hematogones observed by optical microscopy and new cases of acute lymphoblastic leukemia of B-cell precursors were included in the study. Antibodies directed against CD19, CD10, CD45, CD34, IgM and CD22 were used. Analysis of hematogones, using CD10 x CD45 fluorescence intensity as a parameter, showed three sub-populations: immature, intermediary and mature marker expressions. CD34, IgM, TdT and CD22 marker expressions reinforced these results. The leukemic blasts cells formed a single population with positive expression for only immature antigens. In conclusion, hematogones and blast cells demonstrated different immunophenotypic profiles. Hematogones exhibit a broad spectrum of immature, intermediary and mature cells in one sample and blast cells have essentially immature features. Rev. bras. hematol. hemoter. 2006;28(4):258-263.
\end{abstract}

Key words: Hematogone; flow cytometry; acute lymphoblastic leukemia.

\section{Referências Bibliográficas}

1. Basso G, Lanza F, Orfao A, Moretti S, Castoldi G. Clinical and biological significance of CD34 expression in acute leukemia. J Biol Regul Homeost Agents 2001;15:66-78.

2. Bene MC, Castoldi G, Kinapp W, Ludwig Hd, Matutes A, Orfao A et al. Proposal for the immunological classification of acute leukemias. Leukemia 1995;9:1.783-1.786.

3. Caldwell CW, Poje E, Helikson MA. B-cell precursor in normal pediatric bone marrow. Am J Clin Pathol 1991:95:816-823.

4. Davis RE, Longacre TA, Cornbleet PJ. Hematogones in the bone marrow of adults. Hematopathology 1993:102(2):202-211.

5. Francés MA. El linfoblasto en la leucemia liinfoblástica aguda: morfologia y citoquímica. Haematologica 2002;87, supl. 1: 259-262. Edição especial.

6. Longacre TA, Foucar K, Crago S, Chen I-M, Griffith B, Dressler L, et al. Hematogones: A multiparameter analysis of bone marrow precursor cells. Blood 1989;73(20):543-552.

7. McKenna RW, Washington LT, Aquino DB, Picker LJ, Krokt SH. Immunophenotypic analysis of hematogones (B-lymphocyte precursors) in 662 consecutive bone marrow specimens by 4color flow cytometry. Blood 2001;98( 8): 2.498-2.507.

8. Rimsza LM, Douglas VK, Tighe P, Saxonhouse MA, Calhoun DA, Christensen RD, et al. Benign B-cell precursors (hematogones) are the predominant lymphoid population in the bone marrow of preterm infants. Biol Neonate 2004;86:247-253.

9. Rimsza LM, Larson RS, Winter SS, Foukar K, Chong Y-Y, Garner $\mathrm{KW}$, et al. Benign hematogone-rich lymphoid proliferations can be distinguished from B-lineage acute lymphoblastic leukemia by integration of morphology, immunophenotype, adhesion molecule expression and architectural features. Am J Clin Pathol 2000;114 (1):66-75.
10. Ryan DH, Chapple CW, SA; Kossover AA, Sandberg AA, Cohen HJ. Phenotypic similarities and differences between CALLApositive acute lymphoblastic leukemia cells and normal marrow CALLA-positive B cell precursors. Blood 1987;70(3):814-821.

11. Vidriales MB, Pérez JJ, López-Berges MC, Gutiérrez N, Ciudad J, Vazquez L, et al. Inmunofenotipo del linfoblasto normal y patológico y sus implicaciones en la detección de enfermedad residual mínima em la leucemia aguda linfoblástica (LAL) del adulto. Haematologica 2002;87, supl. 1:262-267. Edição especial.

12. Wells DA, Sale GE, Shulman HM, Myerson D, Bryant EM, Gooley $\mathrm{T}$, et al. Multidimensional flow cytometry of marrow can differentiate leukemic from normal lymphoblasts and myeloblast after chemotherapy and bone marrow transplantation. Am J Clin Pathol 1998;110:84-94.

Avaliação: Editor e dois revisores externos Conflito de interesse: não declarado

Recebido: 27/03/2006

Aceito: 12/06/2006 